\title{
A Compact Wide-Band Hybrid Dielectric Resonator Antenna with Enhanced Gain and Low Cross-Polarization
}

\author{
Feibiao Dong, ${ }^{1}$ Limei Xu, ${ }^{1}$ Wenbin Lin, ${ }^{2}$ and Tianhong Zhang ${ }^{1}$ \\ ${ }^{1}$ Department of Aeronautics and Astronautics, University of Electronic Science and Technology of China, West Hi-Tech Zone, \\ Xiyuan Road 2006, Chengdu, Sichuan 611731, China \\ ${ }^{2}$ Institute of Electromagnetics, Southwest Jiaotong University, No. 111 North 1st Section of Second Ring Road, Chengdu 610031, China
}

Correspondence should be addressed to Feibiao Dong; feibiaodong@163.com

Received 9 January 2017; Accepted 6 February 2017; Published 26 April 2017

Academic Editor: Miguel Ferrando Bataller

Copyright (C) 2017 Feibiao Dong et al. This is an open access article distributed under the Creative Commons Attribution License, which permits unrestricted use, distribution, and reproduction in any medium, provided the original work is properly cited.

By loading two printed patches to the dielectric resonator antenna (DRA), a compact wide-band hybrid dielectric resonator antenna with enhanced gain and low cross-polarization is presented. The proposed antenna utilizes a combination of a rectangular dielectric resonator and two printed patches. Due to the hybrid design, multiple resonances were obtained. By adding two air layers between the dielectric resonator and the printed patches, the bandwidth has been significantly improved. Compared to the traditional hybrid dielectric resonator antenna, the proposed antenna can achieve wide bandwidth, high gain, low cross-polarization, and even small size simultaneously. The prototype of the proposed antenna has been fabricated and tested. The measured $-10 \mathrm{~dB}$ return loss bandwidth is $25.6 \%(1.7-2.2 \mathrm{GHz})$. The measured antenna gains are about 6.3 and $8.2 \mathrm{dBi}$ in the operating frequency band. Low cross-polarization levels of less than $-28.5 \mathrm{~dB}$ and $-43 \mathrm{~dB}$ in the E-plane and $\mathrm{H}$-plane are achieved. Moreover, the overall dimensions of the antenna are only $67 \times 67 \times 34\left(\mathrm{~mm}^{3}\right)$. The proposed antenna is especially attractive for small base antenna applications.

\section{Introduction}

With the great development in wireless communication systems, their requirements have presented many challenges to the antenna community in terms of miniaturized size, wide bandwidth, improved radiation, and ease of fabrication and integration. For nearly two decades, both the microstrip antennas and the dielectric resonator antennas (DRAs) have been under investigation for modern communication systems; these antennas have many attractive features in terms of low profile, light weight, simple coupling, and ease of fabrication. The dielectric resonator antenna (DRA) has been under investigation over the past two decades and is now being introduced as good candidate for many wireless communication applications [1]. DRA offers many advantages of small size, simple coupling schemes, and high radiation efficiency. As it is known, conventional DRA usually suffers from a limited impedance bandwidth and low antenna gain [2]. DRA working in its fundamental mode radiates like a short dipole; it can achieve broadside radiation patterns with a maximum directivity of about $5 \mathrm{~dB}$ [3]. Substantial efforts have been made to enhance the bandwidth and gain of the DRA. Hybrid resonator antenna techniques [4-6] were proposed to widen the bandwidth of the DRA. The aperture coupled hybrid DRA can achieve wide bandwidth and satisfactory radiation patterns $[4,5]$. In [6], the ultrawideband DRA is excited by a bevel-shaped patch with a coplanar waveguide fed ground. In [7], the proposed DR loaded patch antenna achieves significant reduction in dimensions, but the trade-offs are narrow bandwidth and degradation of the radiation patterns.

Different feed mechanisms used to excite the DRA were proposed to enhance the bandwidth [8-11]. In [8], the MIMO rectangular DRA excited by coplanar waveguide and coaxial probe can achieve $47 \%$ and $25 \%$ impedance bandwidth for port 1 and port 2, respectively. By adopting the strip- and slot-fed excitation schemes, a dual-band and wide-band dualpolarized cylindrical DRA with high port isolation and stable radiation patterns was investigated in [9], but the dimensions of the cylindrical DRA are too large. In the design of [10], a compact dual-polarized DRA fed by a coplanar waveguide is presented. However, the bandwidth for both ports is narrow. In [11], a new wide-band switched line couple was used in the 


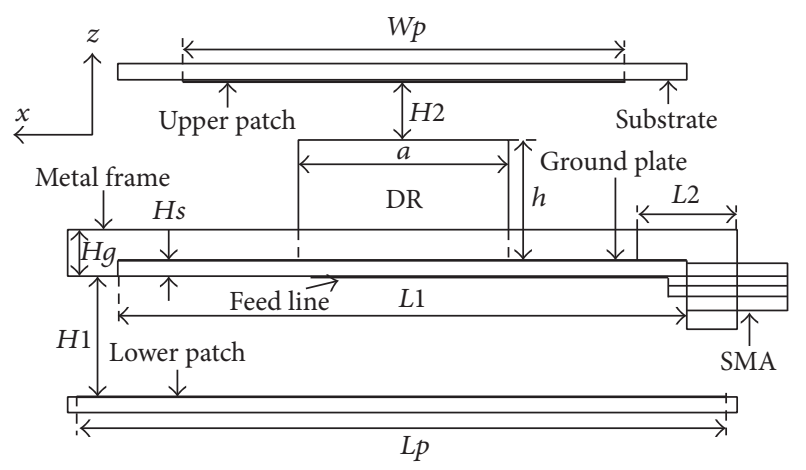

(a)

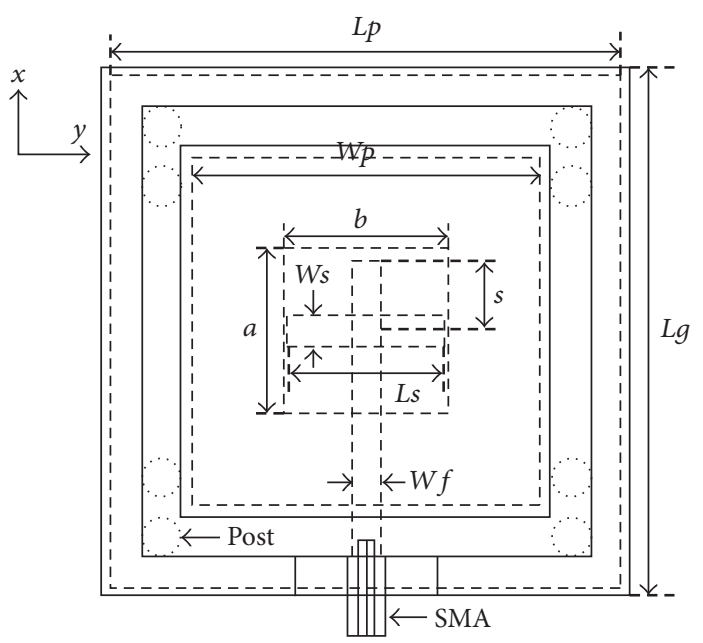

(b)

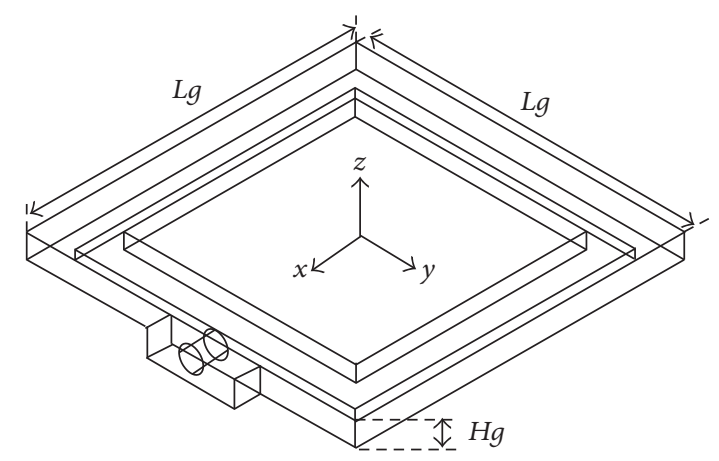

(c)

FIgURE 1: Geometry of the proposed DRA. (a) Side view. (b) Top view. (c) Metal frame.

design of broadband circularly polarized DRA, resulting in a $3 \mathrm{~dB}$ axial ratio bandwidth of $47.69 \%$.

In [12], the authors presented a microstrip feed high aspect ratio DRA with wide bandwidth and miniaturized antenna structure. The main disadvantages of this method are being low in antenna gain and difficulty to design a dualpolarized DRA. Reshaping geometry of a DRA has also been used to widen the bandwidth $[13,14]$. In [15], the authors first introduce $\mathrm{TEx}_{\delta 01}$ in the hybrid DRA design. The proposed DRA has good broadside radiation patterns but with limited bandwidth and difficult fabrication.

In this article, a compact wide-band DR loaded two-patch antenna is presented, comprising a rectangular coupling slot cut in the ground plane and a feeding line printed on the bottom layer of the grounded substrate. The aperture coupled DR acts as the primary radiator and is considered to resonate at the middle frequency. The parasitic metallic patches are supposed to resonate at the lower and higher frequencies, respectively, which can enhance the operating impedance bandwidth of the proposed antenna. A parametric study is performed to understand how the dimensions of the antenna affect the performances. Simulated and measured results show that the proposed antenna element is suitable for the base station antenna that is required to cover the working frequency band of DCS, PCS, and 3G mobile communication systems. Details of the proposed antenna are described, and obtained experimental results are presented and discussed.

\section{Antenna Analysis and Design}

The configuration of the proposed antenna is illustrated in Figure 1. The antenna is composed of a rectangular DR, an upper square patch, a lower square patch, three layer substrates, and eight cylindrical posts. A rectangular DR has one more degree of freedom than cylindrical and spherical DRAs [17]. The DR is situated at the center of the ground plane and fed by a microstrip line through a rectangular slot etched in the ground plane; one end of the feed line is connected to an SMA connector, and the other end extends a stub length $s$ beyond the center of the coupling slot. The DR has length $a$, width $b$, height $h$, and dielectric constant of $\varepsilon_{r}=12$. In order to make the antenna structure more stable, a metal frame with certain structure shown in Figure 1(c) is proposed. The grounded substrate is embedded in the metal frame. The two square patches with thickness of $0.035 \mathrm{~mm}$ are printed on two substrates, respectively, and the two substrates are supported and fixed to the surface of the metal frame by dielectric posts (made of Teflon with relative permittivity of 2.08). 


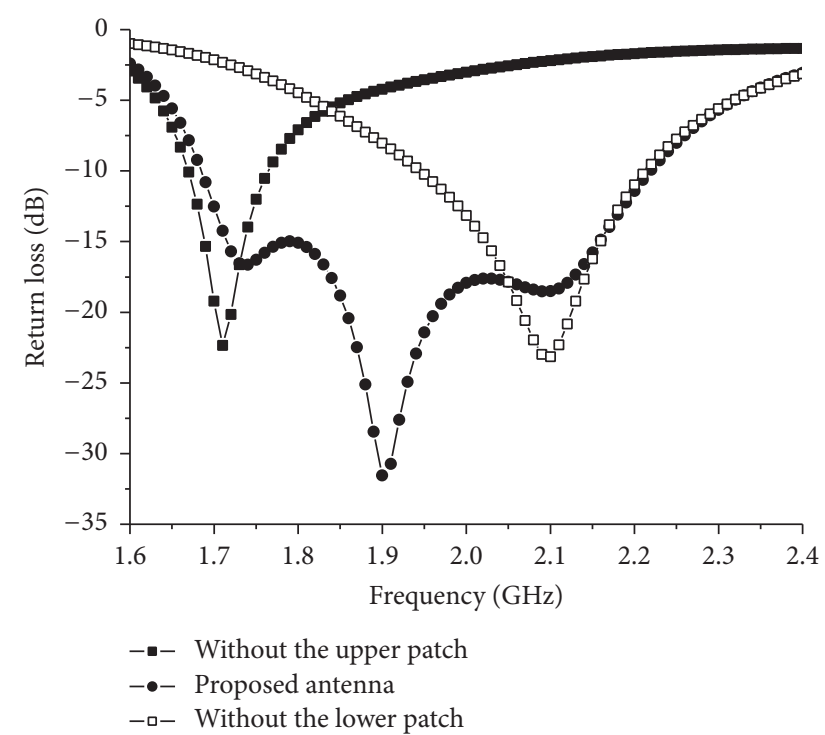

FIGURE 2: Simulated return loss against frequencies for the antenna without the loaded patches compared with the proposed antenna.

The three layer substrates used above are made of FR4 with relative permittivity of 3.38 and a loss tangent of 0.0037 . The key parameters of the antenna are optimized for good performance, and the final dimensions are chosen as follows: $L g=67 \mathrm{~mm}, L p=65 \mathrm{~mm}, L 1=57 \mathrm{~mm}, L 2=10 \mathrm{~mm}$, $W p=44 \mathrm{~mm}, L s=20 \mathrm{~mm}, W s=4 \mathrm{~mm}, W f=3.6 \mathrm{~mm}$, $H g=4.6 \mathrm{~mm}, H s=1.6 \mathrm{~mm}, H 1=12 \mathrm{~mm}, H 2=6 \mathrm{~mm}$, $a=21 \mathrm{~mm}, b=21 \mathrm{~mm}, h=12 \mathrm{~mm}$, and $s=7 \mathrm{~mm}$.

To demonstrate the usefulness of the loaded patches, the antennas without the upper patch and lower patch were analyzed as illustrated in Figure 2. It can be observed from Figure 2 that the resonant frequencies are supposed to be determined by the DR and the two loaded patches. The DR is considered to resonate at the middle frequency of $1.9 \mathrm{GHz}$, and the upper patch and the lower patch are considered to resonate at $2.1 \mathrm{GHz}$ and $1.72 \mathrm{GHz}$, respectively. Electromagnetic energy is coupled to the DR through a rectangular slot cut in the ground plane. The aperture coupled DR acts as the primary radiator and the loaded patches act as the parasitic ones. With the introduction of the parasitic elements, additional resonant frequencies $(1.72 \mathrm{GHz}$ and $2.1 \mathrm{GHz}$ ) close to that of the dielectric resonator antenna are obtained; thus the antenna bandwidth can be significantly improved as shown in Figure 2. More details about the effect of the loaded patches on the antenna performances will be addressed later.

The higher-order modes of rectangular DRAs can be used for enhanced gain design [16], but the DRs have high profile and limited bandwidth. Owing to the loaded patches, the higher-order mode $E_{113}^{x}$ of the DR at $1.9 \mathrm{GHz}$ is excited, while the height of the DR is relatively small. The simulated electric field distribution in the DR is plotted in Figure 3. In addition, by properly optimizing the size and location of the patches, good performance in radiation patterns, gain, and bandwidth can be achieved. Surface current distribution

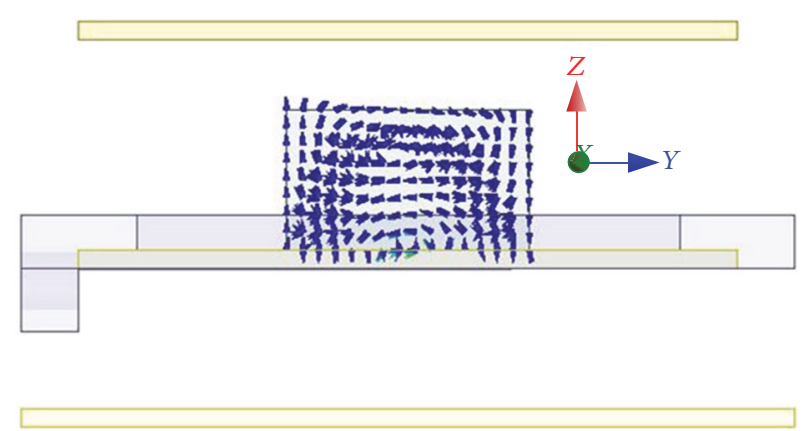

FIGURE 3: Simulated electric field distributions in the DR at $1.9 \mathrm{GHz}$.

TABLE 1: Comparison of the dielectric resonator antennas.

\begin{tabular}{lcccc}
\hline Reference & $f_{0}(\mathrm{GHz})$ & BW $(\%)$ & Peak gain $(\mathrm{dBi})$ & X-pol $(\mathrm{dB})$ \\
\hline$[4]$ & 5.8 & 23.5 & 7.5 & -18 \\
{$[5]$} & 5.5 & 28.9 & 3.8 & -15 \\
{$[7]$} & 1.71 & 6.3 & 5 & -18 \\
{$[10]$} & 3.73 & 11.6 & 6.45 & -20 \\
{$[12]$} & 7.45 & 17 & 5 & -15 \\
{$[16]$} & 11 & 8.3 & 10.2 & -20 \\
{$[15]$} & 3.5 & 2.4 & 5.72 & -20 \\
Proposed & 2 & 25.6 & 8.2 & -28.5 \\
\hline
\end{tabular}

on the loaded patches for the horizontal polarization is illustrated in Figure 4. It can be seen that the current is approximately uniformly distributed along $y$-axis, which contributes to reducing the cross-polarization. In Figure 4(a), the currents are mainly distributed on the two edges of the upper patch along $x$-axis, while in Figure 4(b) the currents are mainly distributed on the two edges of the lower patch along $y$-axis. Because of this kind of current distribution on the two loaded patches, good and stable unidirectional radiation patterns can be obtained.

Table 1 is listed to understand some achievement in dielectric resonator antennas. The comparison gives performances including bandwidth, gain, size, and crosspolarization. From Table 1, it can be seen that most of the traditional hybrid antenna designs could not achieve over $7 \mathrm{dBi}$ antenna gain and have relatively high crosspolarization levels. Compared with these hybrid dielectric resonator antennas, the proposed antenna has an appreciable gain enhancement while maintaining good performances of bandwidth, size, and cross-polarization.

Compared with the wide-band DRA, it seems that the proposed technique is not impressed. But we have to mention that the bandwidth of the proposed antenna can be further extended by properly adjusting some parameters. Take the parameter $W p$, for example, the bandwidth can increase to $31.3 \%$ from previous $25.6 \%$ as shown in Figure 9(a). Because of the main focus on the applications that are required to cover the working frequency band from 1.7 to $2.2 \mathrm{GHz}$, the aim of the design is to make the return loss in the working frequency band as small as possible. 


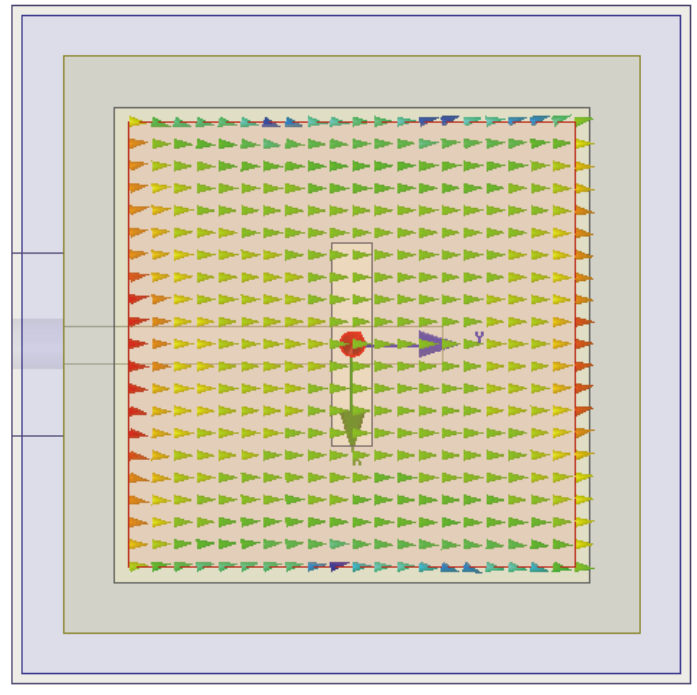

(a)

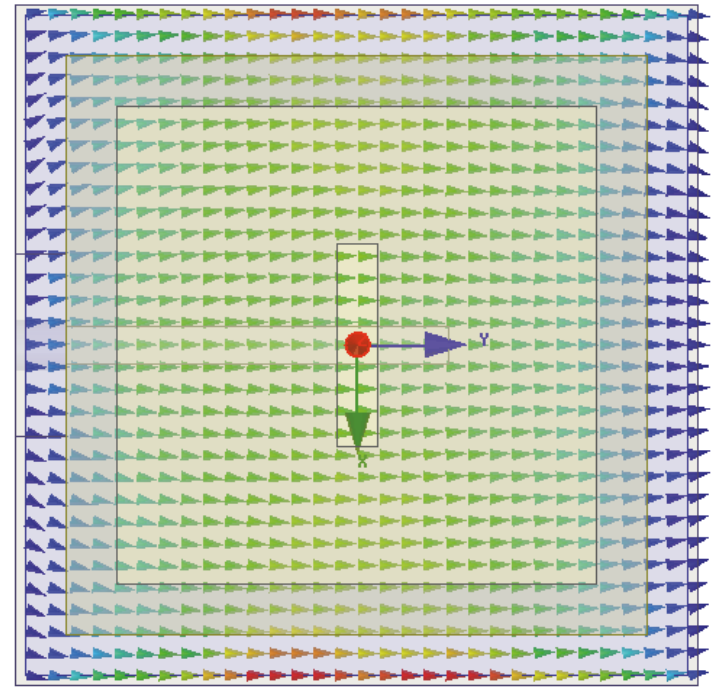

(b)

Figure 4: Surface current distributions. (a) Upper patch at $2.1 \mathrm{GHz}$. (b) Lower patch at $1.72 \mathrm{GHz}$.

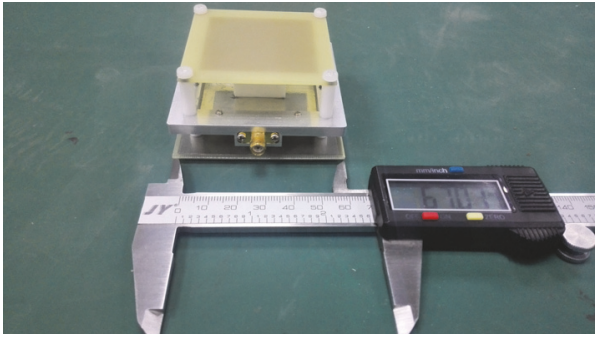

(a)

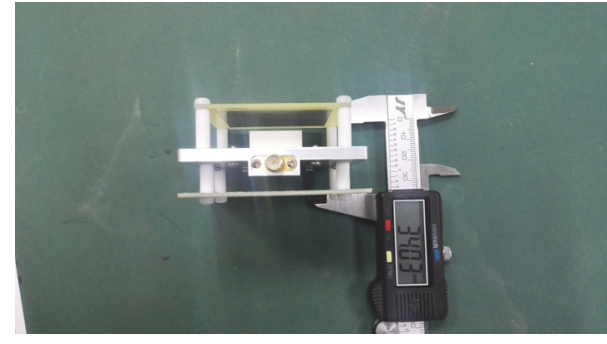

(b)

FIgURE 5: Photographs of the proposed DRA. (a) 3D view and (b) side view.

\section{Results and Discussion}

To demonstrate the validity of the above hybrid design, an antenna prototype according to the optimized parameters has been fabricated and measured, and its performance has been simulated by ANSYS HFSS. A prototype of the proposed DR antenna fabricated according to the optimized parameters is shown in Figure 5.

Figure 6 illustrates the simulated and measured return loss. The measured $-10 \mathrm{~dB}$ return loss bandwidth is $25.6 \%$ from 1.7 to $2.2 \mathrm{GHz}$. The simulated and measured gains in the operating frequency band are depicted in Figure 7. An average measured gain of $7.54 \mathrm{dBi}$ is found over the operating frequencies. The simulated and measured radiation patterns at $2 \mathrm{GHz}$ are depicted in Figure 8. It can be seen that the proposed antenna radiates a maximum power towards the broadside direction. The simulated cross-polarization levels in the E-plane and $\mathrm{H}$-plane are less than $-33.8 \mathrm{~dB}$ and $-49.6 \mathrm{~dB}$. The measured cross-polarization levels in the E-plane and $\mathrm{H}$-plane are below $-28.5 \mathrm{~dB}$ and $-43 \mathrm{~dB}$, respectively, and the measured cross-polarization level is higher than the simulated results.
In order to investigate how the dimensions of the antenna affect the antenna performances, a parametric study has been performed.

Figure 9 shows the effect of the width of the upper patch Wp. This parameter determines both the resonant frequencies and antenna gains at the high end of the frequency band. With the decrease of Wp, the high end of the frequency band expands significantly, while the low end of the frequency band changes slightly. The bandwidth of the proposed antenna can be further extended by properly adjusting the width of the upper patch. The antenna gains at higher frequencies can be increased by about $0.4 \mathrm{dBi}$ when $W p$ increases to $48 \mathrm{~mm}$ from $39 \mathrm{~mm}$, but the impedance matching for higher frequencies turns bad seriously, which is suitable for wide-band design.

Figure 10 shows the effect of the width of the lower patch Lp. This parameter determines both the resonant frequencies and antenna gains at the low end of the frequency band. With the increase of $L p$, the low end of the frequency band moves closer to the lower operating frequency, while the high end of the frequency band changes slightly. The antenna gains at lower frequencies together with the bandwidth will 


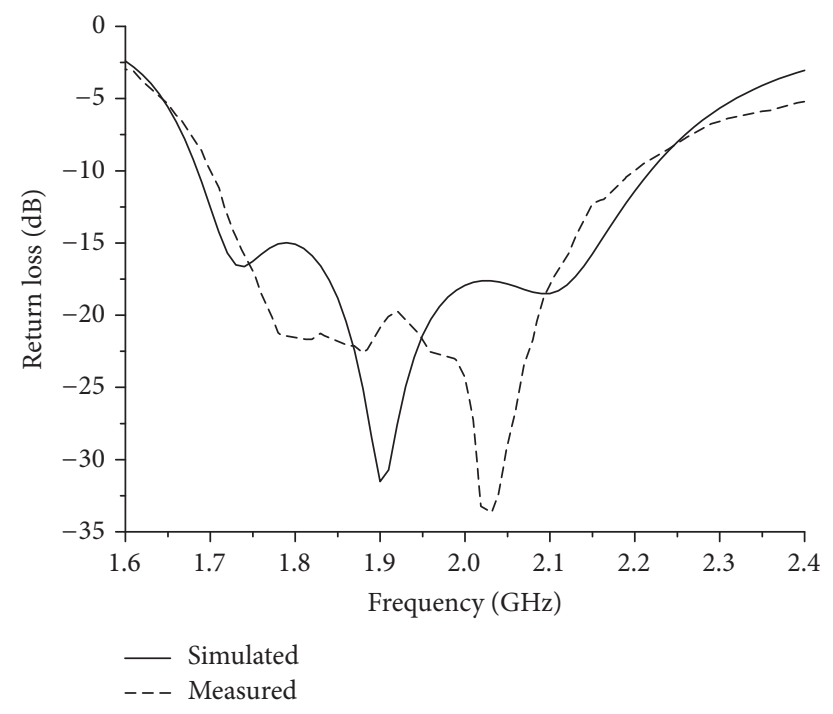

FIGURE 6: Return loss against frequency of the proposed DRA.

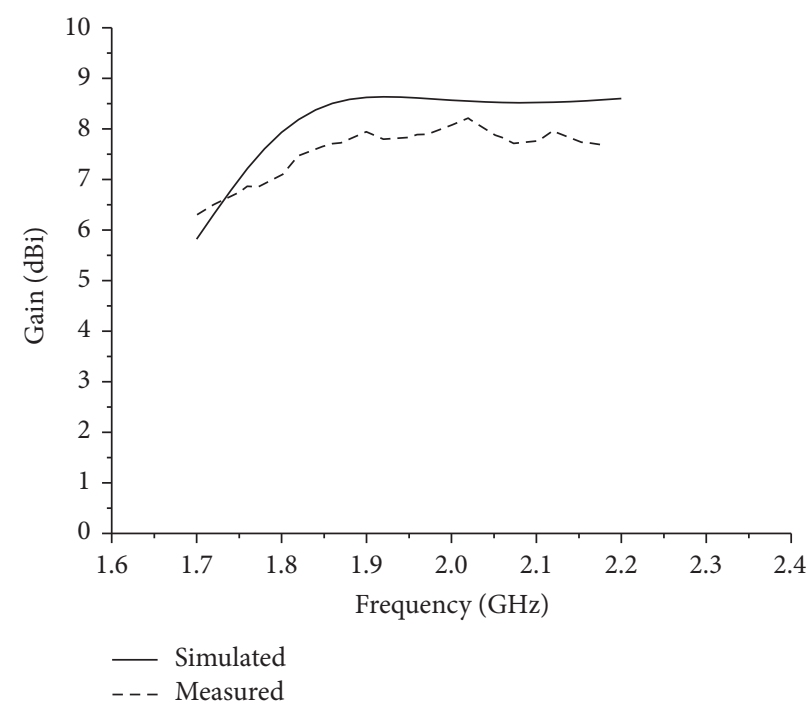

FIGURE 7: Antenna gains against frequency of the proposed DRA.

be significantly reduced when $L p$ decreases to $55 \mathrm{~mm}$ from $70 \mathrm{~mm}$. Therefore, larger $L p$ can enhance the antenna gains at lower frequencies and expand the bandwidth of the proposed antenna.

Figure 11(a) shows the simulated return loss versus frequency with different $H 1$ and $H 2$. It can be seen from the figuration that if $H 1$ is too small, take $10 \mathrm{~mm}$, for example, the reflection coefficients between 1.7 and $1.8 \mathrm{GHz}$ get close to $-10 \mathrm{~dB}$, which is not for wide-band design. When $H 1$ is too large, the impedance matching for middle end of the frequency band turns bad. Thus, the optimized value for $\mathrm{H} 2$ is chosen to be $12 \mathrm{~mm}$. With the variation of $\mathrm{H} 2$, the reflection coefficients change slightly in the lower working frequency band, while, as depicted in Figure 9, we can find that the impact of $\mathrm{H} 2$ on the impedance matching is significant at the higher frequency band. With the variation of $\mathrm{H} 2$ from $5 \mathrm{~mm}$ to $7 \mathrm{~mm}$, the impedance matching between 1.9 and $2.14 \mathrm{GHz}$ becomes bad.

In the E-plane, the simulated cross-polarization levels in the broadside direction against the frequency with $H 1$ and $\mathrm{H} 2$ are displayed in Figure 11(b). Observe that the crosspolarization decreases significantly as $H 1+H 2$ increases from $16 \mathrm{~mm}$ to $20 \mathrm{~mm}$. When $H 1$ is chosen to be $12 \mathrm{~mm}$ or $14 \mathrm{~mm}$, the average cross-polarization remains below the $-40 \mathrm{~dB}$ level; considering the compact design for the design, the optimum value of $H 1$ has been chosen to be $12 \mathrm{~mm}$. Varying $\mathrm{H} 2$ from $5 \mathrm{~mm}$ to $7 \mathrm{~mm}$, it can be seen that both the bigger $\mathrm{H} 2$ and the smaller $\mathrm{H} 2$ will bring about high cross-polarization levels. Through the parametric study, the optimum value for $\mathrm{H} 2$ was chosen to be $6 \mathrm{~mm}$. 


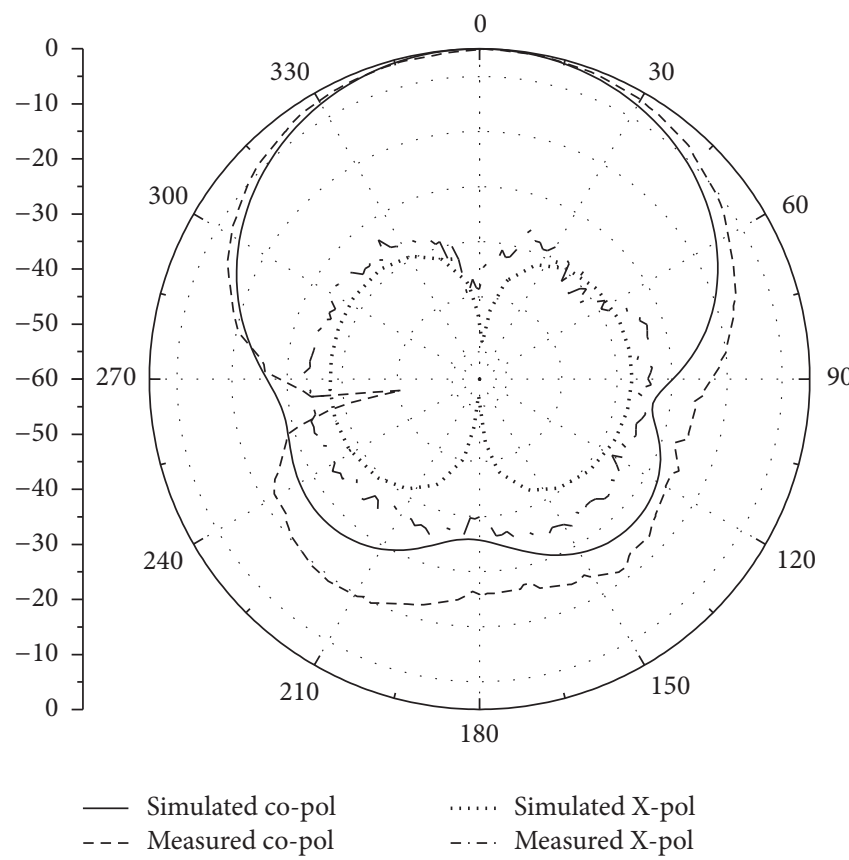

(a) E-Plane

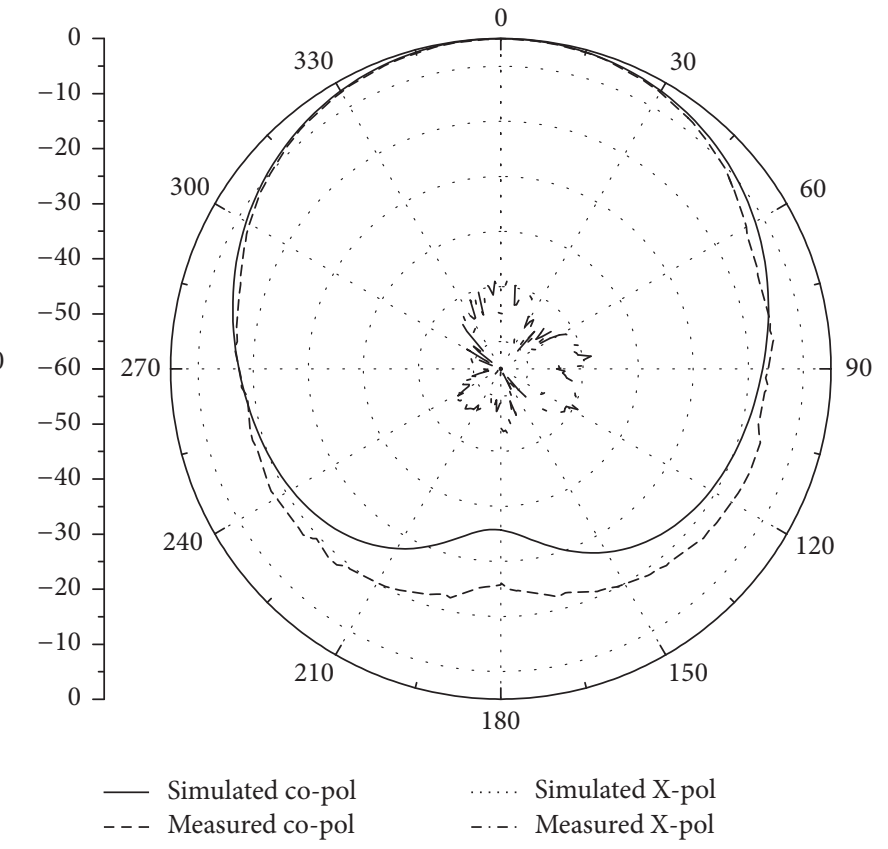

(b) H-Plane

FIGURE 8: Simulated and measured radiation patterns of the proposed antenna at $2 \mathrm{GHz}$.

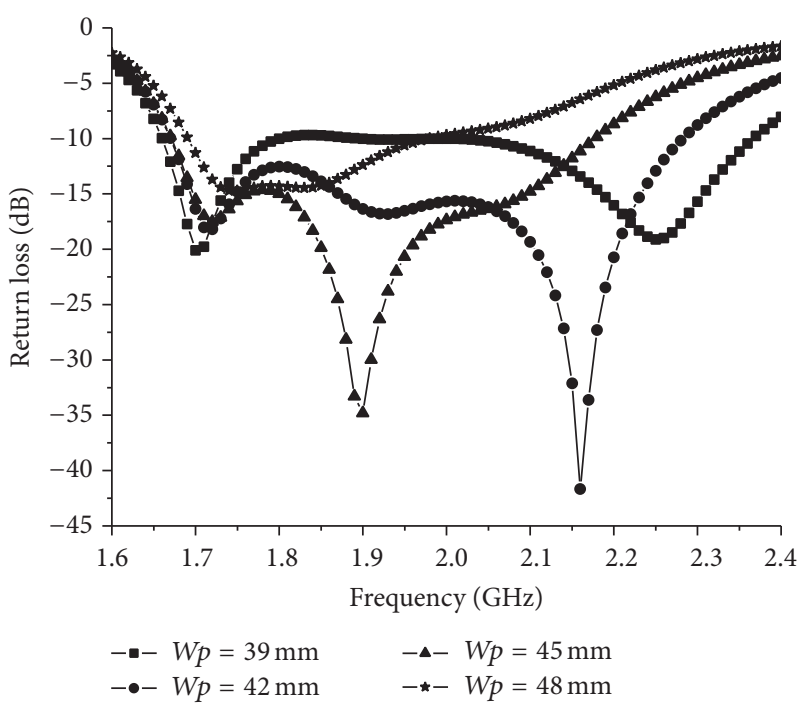

(a)

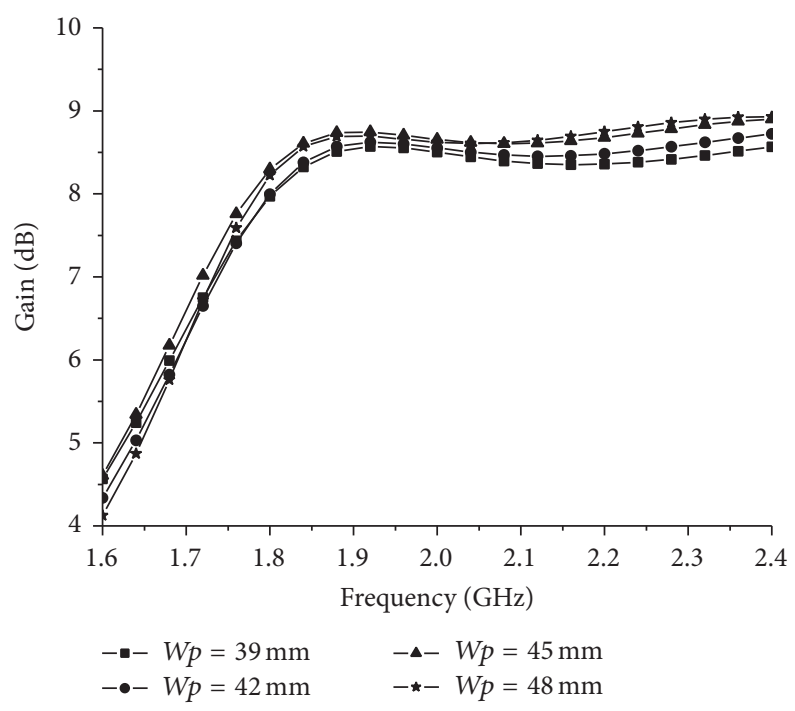

(b)

Figure 9: Effect of the width of the upper patch Wp. (a) Return loss. (b) Antenna gains.

\section{Conclusion}

A compact wide-band dielectric resonator loaded patches antenna has been proposed and investigated. With the introduction of the loaded patches, multiple resonant frequencies emerged, which results in wide bandwidth and enhanced antenna gain. Parametric studies illustrate the usefulness of the loaded patches. An antenna prototype was constructed and tested. The measured $-10 \mathrm{~dB}$ return loss bandwidth is
$25.6 \%$ from 1.7 to $2.2 \mathrm{GHz}$. An average gain of $7.54 \mathrm{dBi}$ and unidirectional radiation patterns with low cross-polarization were obtained. Moreover, the antenna structure is simple and compact, which can be developed to form antenna arrays for compact base stations in wireless communications.

\section{Conflicts of Interest}

The authors declare that they have no conflicts of interest. 


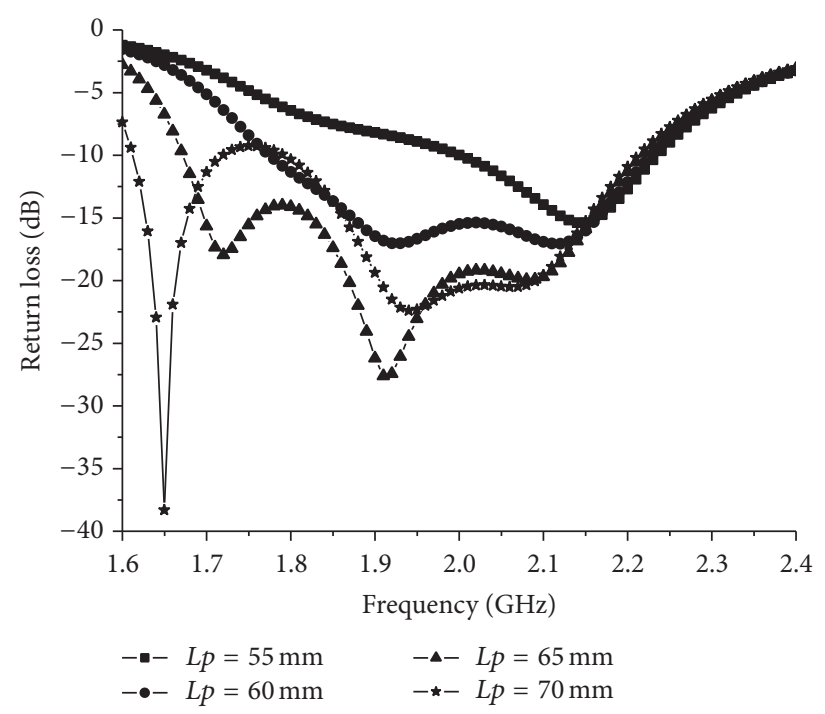

(a)

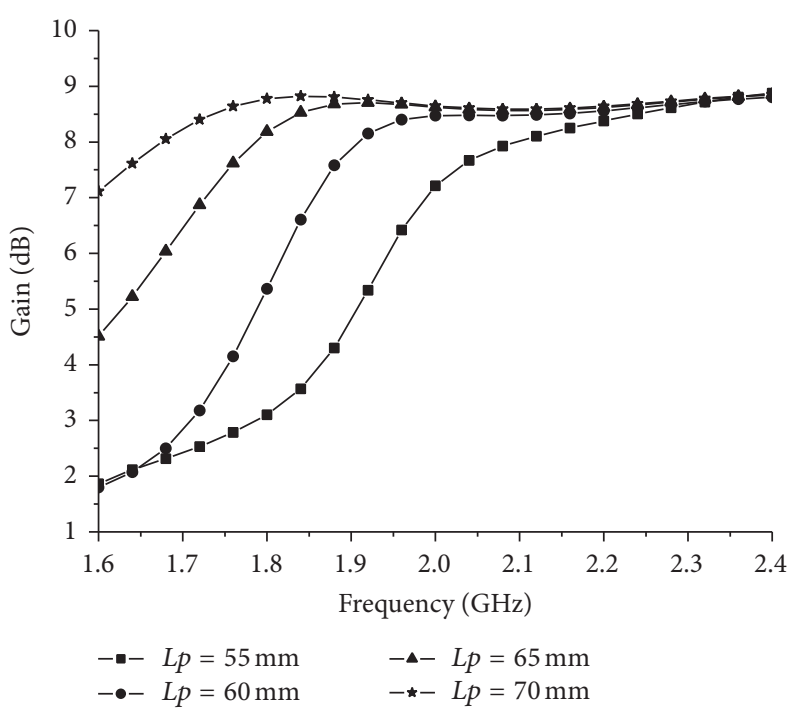

(b)

FIGURE 10: Effect of the width of the lower patch $L p$. (a) Return loss. (b) Antenna gains.

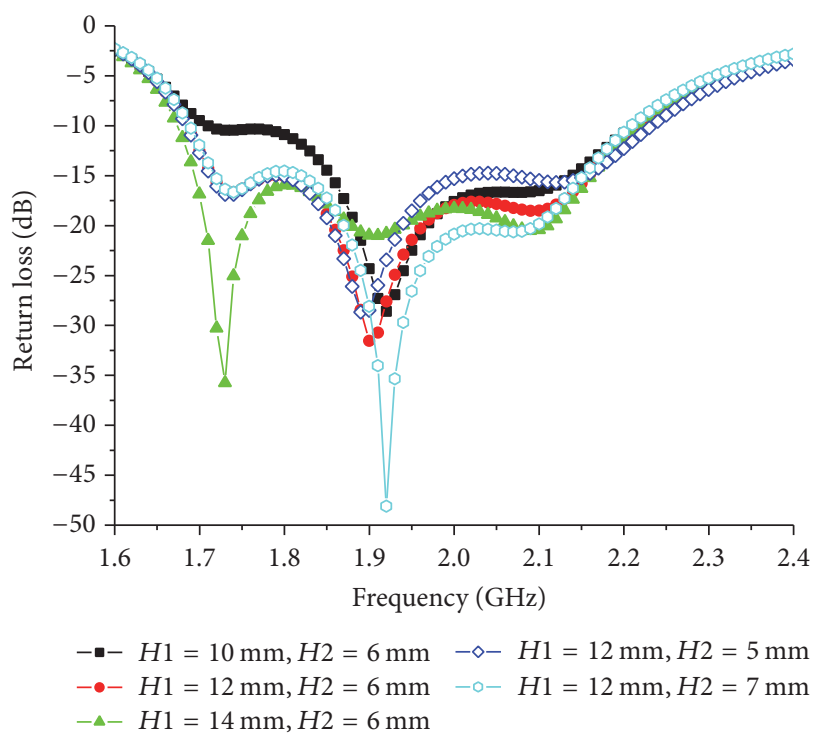

(a)

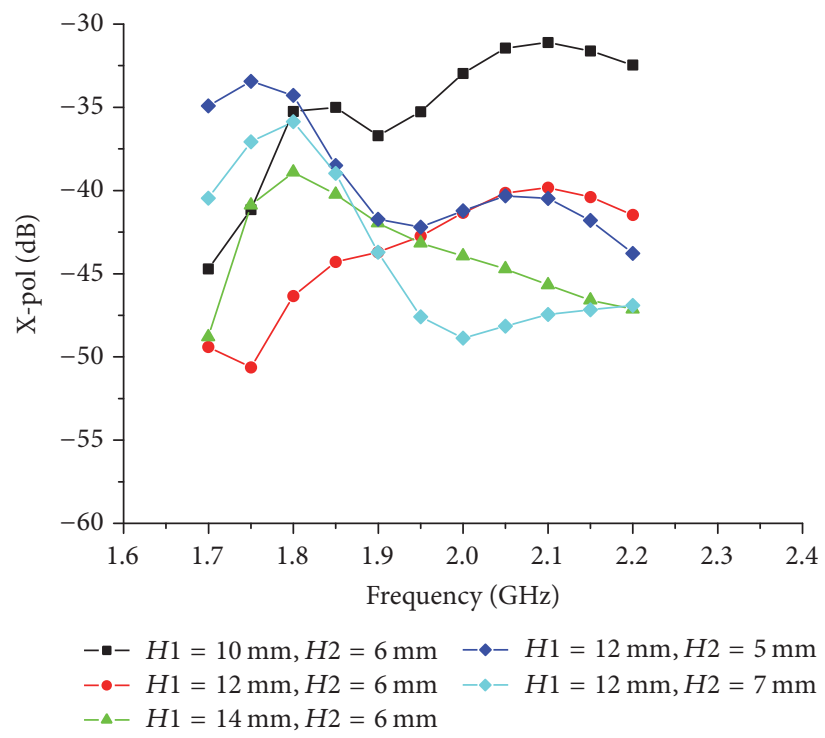

(b)

FIgURE 11: Effect of the parameters $H 1$ and H2. (a) Return loss. (b) Cross-polarization level.

\section{Acknowledgments}

This work is supported in part by the National Natural Science Foundation of China (Grant nos. 61301261 and G0504740161271286).

\section{References}

[1] J. R. James and P. S. Hall, "Characteristics of micro-strip patch antennas and some methods of improving frequency agility and bandwidth," in Handbook of Micro-Strip Antennas, chapter 3, p. Peregrinus, Peregrinus, London, UK, 1989.

[2] A. Petosa, Dielectric Resonator Antenna Handbook, Artech House, Norwood, Mass, USA, 2007.
[3] A. Petosa and A. Ittipiboon, "Dielectric resonator antennas: a historical review and the current state of the art," IEEE Antennas and Propagation Magazine, vol. 52, no. 5, pp. 91-116, 2010.

[4] K. P. Esselle and T. S. Bird, "A hybrid-resonator antenna: experimental results," IEEE Transactions on Antennas and Propagation, vol. 53, no. 2, pp. 870-871, 2005.

[5] Y. Gao, B.-L. Ooi, W.-B. Ewe, and A. P. Popov, "A compact wideband hybrid dielectric resonator antenna," IEEE Microwave and Wireless Components Letters, vol. 16, no. 4, pp. 227-229, 2006.

[6] T. A. Denidni and Z. Weng, "Hybrid ultrawideband dielectric resonator antenna and band-notched designs," IET Microwaves, Antennas and Propagation, vol. 5, no. 4, pp. 450-458, 2011. 
[7] K. Y. Hui and K. M. Luk, "Bandwidth enhancement of small dielectric resonator loaded patch antenna," IEEE Transactions on Antennas and Propagation, vol. 54, no. 6, pp. 1882-1885, 2006.

[8] S. F. Roslan, M. R. Kamarudin, M. Khalily, and M. H. Jamaluddin, "An MIMO rectangular dielectric resonator antenna for $4 \mathrm{G}$ applications," IEEE Antennas and Wireless Propagation Letters, vol. 13, pp. 321-324, 2014.

[9] Y. X. Sun and K. W. Leung, "Dual-band and wideband dual-polarized cylindrical dielectric resonator antennas," IEEE Antennas and Wireless Propagation Letters, vol. 12, pp. 384-387, 2013.

[10] Y. Gao, Z. Feng, and L. Zhang, "Compact CPW-fed dielectric resonator antenna with dual polarization," IEEE Antennas and Wireless Propagation Letters, vol. 10, pp. 544-547, 2011.

[11] R.-C. Han, S.-S. Zhong, and J. Liu, "Broadband circularly polarised dielectric resonator antenna fed by wideband switched line coupler," Electronics Letters, vol. 50, no. 10, pp. 725-726, 2014.

[12] A. Rashidian and D. M. Klymyshyn, "On the two segmented and high aspect ratio rectangular dielectric resonator antennas for bandwidth enhancement and miniaturization," IEEE Transactions on Antennas and Propagation, vol. 57, no. 9, pp. 27752780, 2009.

[13] M. Khalily, M. K. A. Rahim, A. A. Kishk, and S. Danesh, "Wideband P-shaped dielectric resonator antenna," Radioengineering, vol. 22, no. 1, pp. 281-285, 2013.

[14] R. K. Chaudhary, R. Kumar, and K. V. Srivastava, "Wideband ring dielectric resonator antenna with annular-shaped microstrip feed," IEEE Antennas and Wireless Propagation Letters, vol. 12, pp. 595-598, 2013.

[15] Y. Gao, Z. Feng, and L. Zhang, "Experimental investigation of new radiating mode in rectangular hybrid dielectric resonator antenna," IEEE Antennas and Wireless Propagation Letters, vol. 10, pp. 91-94, 2011.

[16] A. Petosa and S. Thirakoune, "Rectangular dielectric resonator antennas with enhanced gain," IEEE Transactions on Antennas and Propagation, vol. 59, no. 4, pp. 1385-1389, 2011.

[17] P. Rezaei, M. Hakkak, and K. Forooraghi, "Design of wide-band dielectric resonator antenna with a two-segment structure," Progress in Electromagnetics Research, vol. 66, pp. 111-124, 2006. 


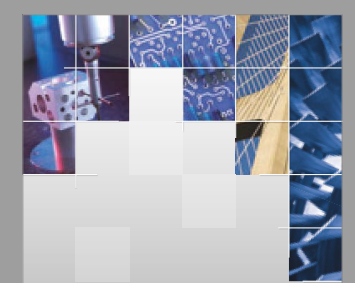

\section{Enfincering}
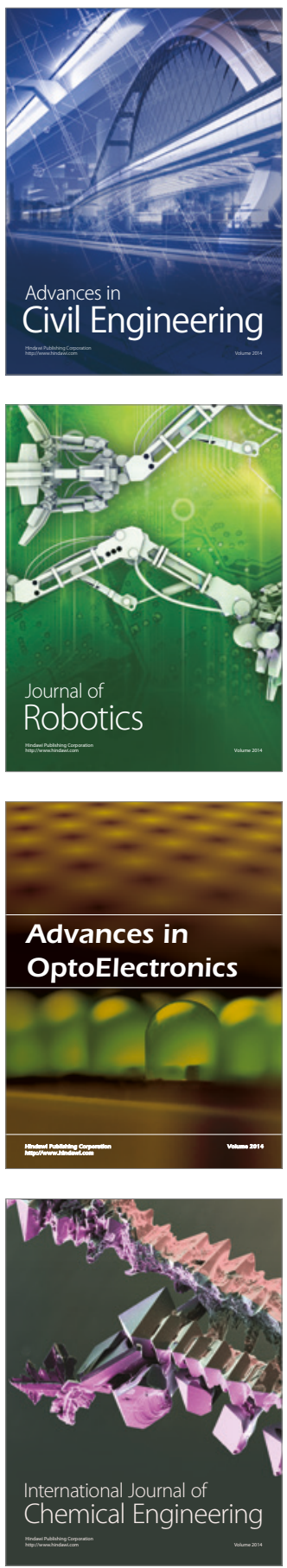

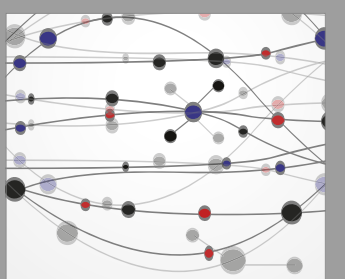

The Scientific World Journal

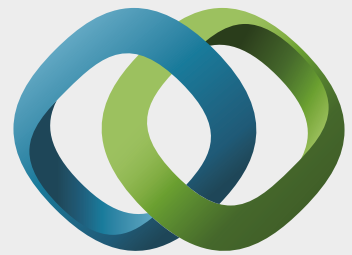

\section{Hindawi}

Submit your manuscripts at

https://www.hindawi.com
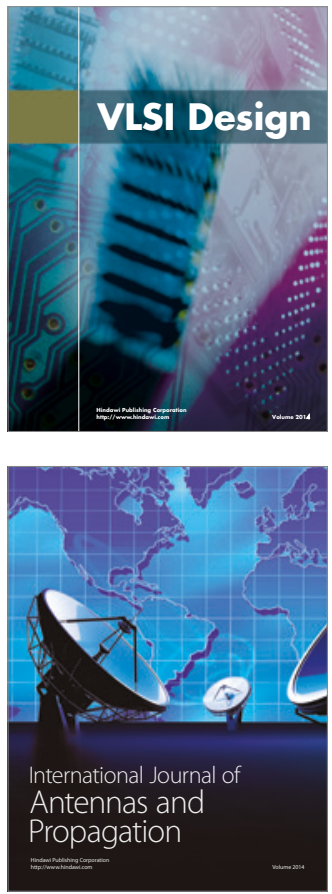

\section{Rotating}

Machinery
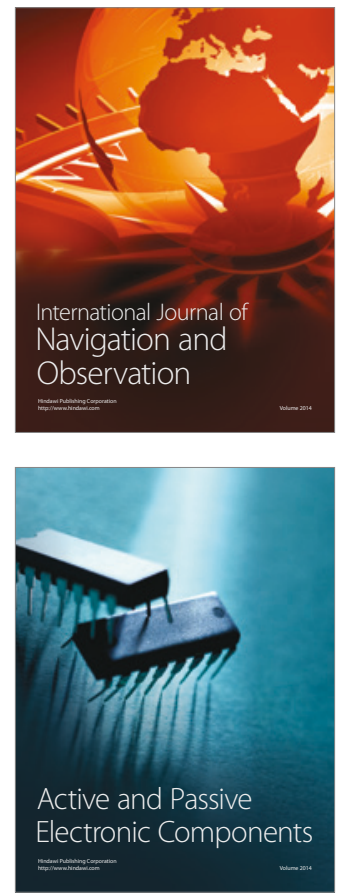
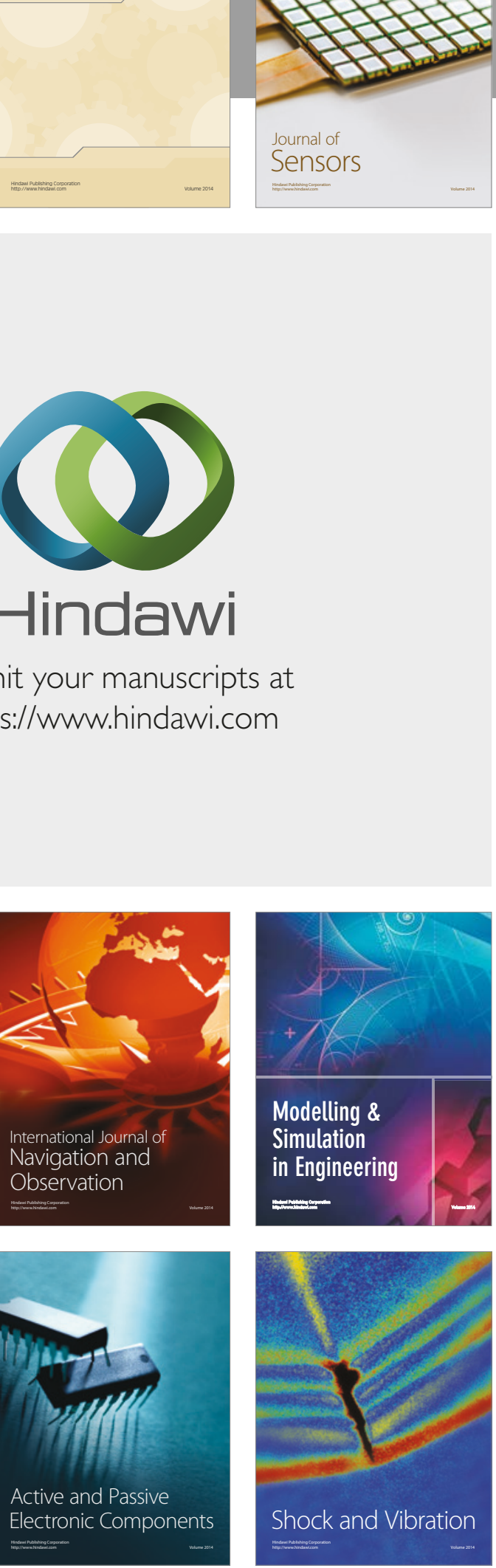
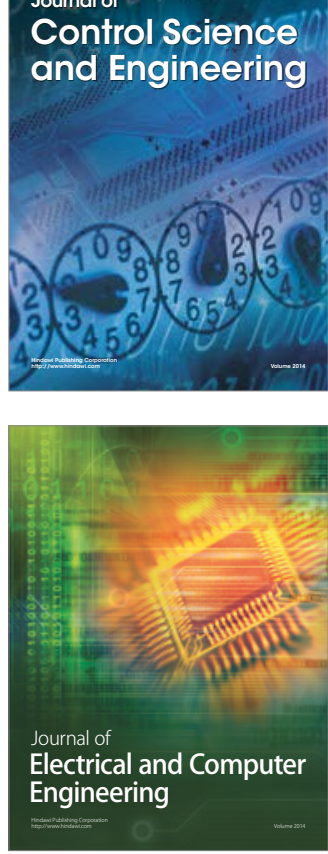

Distributed

Journal of

Control Science

and Engineering
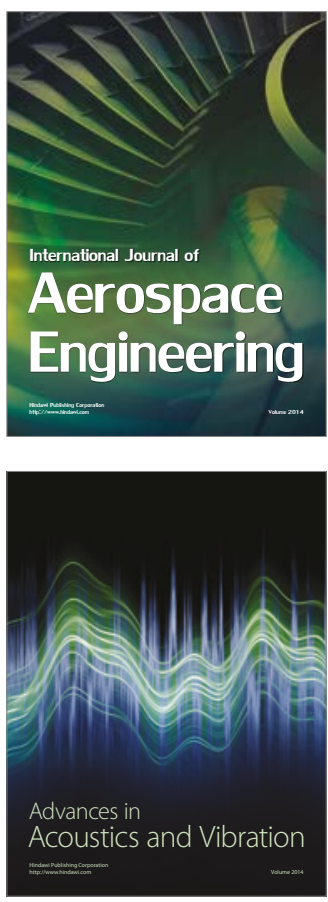

Sensor Networks 